\title{
Foam Roller Kullanılarak Gerçekleştirilen Kendi Kendine Miyofasiyal Gevşetme Egzersizlerinin Esneklik ve Alt Ekstremite Gücü Üzerine Akut Etkisi*
}

\section{Acute Effect of Self-Myofascial Release Using a Foam Roller on Flexibility and Lower Extremity Power}

\author{
ORİJINAL ARAŞTIRMA/ \\ ORIGINAL RESEARCH \\ Ramazan YİTíK ${ }^{\mathbf{1}}$ \\ Bahar ATEŞ $^{2}$
}

${ }^{1}$ Uşak Üniversitesi, Uşak

https://orcid.org/0000-0002-8930-6190

${ }^{2}$ Uşak Üniversitesi, Uşak

https://orcid.org/0000-0002-6339-3564

\begin{abstract}
$\ddot{\mathbf{O z}}$
Bu çalışmanın amacı, titreşimli foam roller kullanılarak kendi kendine uygulanan miyofasiyal gevşetme uygulamalarının alt ekstremite gücü ve esneklik performansı üzerine akut etkisini incelemektedir. Çalışmaya, fiziksel olarak aktif 12 gönüllü sağlıklı genç erkek futbolcu (ortalama yaş: $20.6 \pm 0.4$ yıl) katıldı. Çapraz randomize olarak tasarlanan çalışmada, sporcular, 5 gün ara ile üç farklı egzersize katıldı ve her bir deneme günün aynı saatinde gerçekleştirildi. İlk çalışma gününde alıştırma egzersizleri ve antropometrik ölçümler uygulandı. İkinci çalışma gününde, sporcular aerobik koşu ve dinamik gerdirme $(A R+D G)$ egzersizleri uyguladiktan sonra performans testlerini (sıçrama ve esneklik) uyguladı. Son çalışma gününde sporcular aerobik koşu ve kendi kendine miyofasial gevşetme ( $\mathrm{AR}+\mathrm{KKMG})$ egzersizlerinden sonra aynı testleri tekrar uyguladı. Alt ekstremite kaslarının kalça, sırt ve arka esnekliğini saptamak için OturEriş Testi ve alt ekstremite gücü aktif sıçrama (AS) ve skuat sıçrama (SS) ile Smartjump (Fusionsport) kullanılarak ölçüldü. Performans farklılıklarını belirlemek için Wilcoxon Signed-Rank testi kullanıld1. AR+DG ve AR+KKMG 1sinma protokolleri arasinda sadece AS performansında istatistiksel olarak anlamlı bir fark gözlemlenmedi ( $\mathrm{z}=-2.67$, $\mathrm{p}<0.05)$. AS performansı AR+DG uygulamasında daha yüksek tespit edildi. Sonuç olarak alt ekstremiteye uygulanan 30 sn'lik KKMG egzersizlerinin dikey sıçrama ve esneklik performansı üzerine bir etkisi olmadığı, daha uzun yuvarlanma süreleri ve farklı performans parametrelerinin de test edilmesi önerilmektedir.
\end{abstract}

Anahtar Kelimeler: Futbol, Foam roller, Performans.

\begin{abstract}
The purpose of this study is to investigate the acute effect of self-myofascial release (SMR) applications using a foam roller on jumping and flexibility performance. Twelve physically active, athletic healthy male soccer player (mean age: $20.6 \pm 0.4$ years), voluntarily participated in the study. The experimental design of this study was a Crossover Randomized Study. Each subjects participated in three different experimental conditions on separate visits to the sports hall with a 5 days' interval and each took place at the same time of day. During the familiarization session, anthropometric measurements were taken. Second experimental day, subjects performed aerobic running and dynamic stretching (AR+DS) followed by jumping test and flexibility test, and the other experimental day, subjects performed aerobic running and selfmyofascial-release $(\mathrm{AR}+\mathrm{SMR})$ followed by the same series of athletic performance tests. The sit-and-reach test (S\&R) was applied to determine hip, back and posterior flexibility of the muscles of the lower limbs. The vertical jump height for the countermovement jump (CMJ) and Squat Jump (SJ) were measured using a Smartjump (Fusionsport). Wilcoxon Test $(\mathrm{p}<0.05)$ was used for statistical analysis. A statically significant difference was found in CMJ performance between AR+DS and AR+SMR conditions $(\mathrm{z}=-2.67, \mathrm{p}<0.05)$. The CMJ performance was detected higher mean value in $A R+D S$ than AR+SMR conditions. However, no significant differences were found in SJ and flexibility performance between AR+DS and AR+KKMG conditions (p>0.05). In conclusion, 30-second bouts of lower body SMR foam rolling do not improve vertical jump and flexibility performance. It is recommended to test longer rolling times and different performance parameters.

Keywords: Soccer, Foam roller, Performance.
\end{abstract}

\footnotetext{
*Bu çalışma 7-9 Mayıs 2018 tarihlerinde Manisa'da düzenlenen 5.Uluslararası Spor Bilimleri Turizm ve Rekreasyon Öğrenci Kongresi'nde sözel bildiri olarak sunuldu.

†Sorumlu yazar: Ramazan YİTIK, ramazanyitik20@hotmail.com
} 


\section{GİRIŞ}

Doku üzerine etki eden fiziksel tekniklerden biri olan "Miyofasiyal (miyo-bă̆ dokusal) gevşetme“ (Manheim, 2008), günümüze kadar birçok sakatlık durumda kullanılagelmiş, Barnes (1997) tarafından fizik tedavi ve manipülatif tedavi çevrelerine yaygınlaşmıştır. Günümüzde "miyofasiyal gevşetme" tekniği olarak da tanımlanmaktadır. Teknik anlamda miyofasiyal gevşetme, bir terapi uzmanının yumuşak dokulara uyguladığı ve uygulanan kişinin kaslarındaki geri bildirim aşamasına yönelik olarak uygulama açısı, kuvveti ve süresi değişen, yumuşak dokulardaki kısıtlamaları ortadan kaldırmak için kullanılan aşamalı germe (stretch) olarak ifade edilmektedir (Manheim, 2008).

Miyofasiyal salınımın kas dengesizliğin düzenlenmesi, eklem hareket açıklığının arttırması, kas ağrıları ve eklem sertliğinin ve nöromüsküler artmış tonun azaltılması, müskülotendinöz bileşikteki esnekliğin ve nöromüsküler aktivitenin arttırılması ve normal fonksiyonel kas uzunluğunun sağlanması gibi etkilerin olduğu bilinmektedir. Ancak, bu teknik maliyetli, zaman alıcı ve yetenekli bir klinisyen gerektirmektedir (Robertson, 2008). Bu nedenle, kendi kendine uygulanan miyofasiyal gevşetme sporcular için faydalı bir alternatif olarak gösterilmektedir. Kendi kendine uygulanan miyofasiyal gevşetme ile miyofasiyal gevşetme aynı prensipte olmasına rağmen, iki teknik arasındaki fark, yumuşak dokuya elle uygulama sağlayan bir uzman yerine, kendi kendine uygulanan miyofasiyal gevşetme tekniğinde bir köpük silindir üzerinde, bireyin kendi vücut kütlesini kullanarak yumuşak doku üzerinde bir basınç uygulamasıdır. Kendi kendine uygulanan miyofasial gevşetme tekniği, kasın distal kısmına doğru aşağı doğru çalışan kasın proksimal bölümünde başlayan yoğun bir köpük silindiri üzerinde ileri ve geri küçük dalgalanmalar içermektedir (Power ve ark., 2004). Yapılan çalışmalar, egzersiz öncesi kendi kendine uygulanan miyofasiyal gevşetme uygulamasının miyofasiyal salınım yoluyla sportif performansı arttırabileceğini ve bunun da artmış hareketlilik ve artmış nöromüsküler etkinliğe yol açabileceğini iddia etmektedir (Castiglione, 2010). Son zamanlarda, sporcularda kendi kendine uygulanan miyofasyal gevşetme uygulamalarının performans arttırmak amacıyla uygulanan egzersiz öncesi bir teknik olarak kabul edildiği de bazı çalışmalarda belirtilmektedir (MacDonald ve ark., 2013; Okamoto ve ark., 2013; Renan-Ordine ve ark., 2011). Masajda olduğu gibi, bir egzersizden önce köpük yuvarlanmanın kas-uzunluk-gerginlik ilişkilerini düzeltmeye yardımcı olduğu ve daha iyi ısınmaya imkan verdiği söylenmektedir (Depino ve ark., 2000). Fakat 
bu etkilerin bazıları kanıtlanmıştır ve ilgili literatür yeterince kapsamlı değildir. Örneğin, Beardsley ve Skarabot (2015), esneklik, kuvvet üretimi, performans ve kas ağrısının gecikmiş başlangıcında köpük-yuvarlama egzersizlerinin çelişkili sonuçlarını göstermiştir.

Bu bilgilerden yola çıkarak, bu çalışma kapsamında, son zamanlarda spor bilimlerinde, özellikle takım sporlarında yaygın olarak kullanılmaya başlayan, bir sporcunun nöromüsküler işlevinin arttırabileceği ileri sürülen ve dinamik kuvvet üretim yetenekleri üzerindeki etkileri hakkında çok az kanıt bulunan ve kendi kendine uygulanan Vyper Titreşimli Foam Roller uygulamasının, genç erkek futbolcularda esneklik, AS ve SS parametreleri üzerine akut etkisini incelemek amaçland1.

\section{YÖNTEM}

\section{Çalışma Grubu}

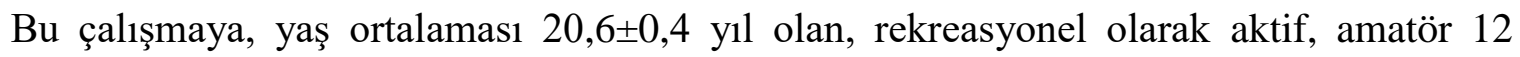
gönüllü genç sağlıklı erkek futbolcu örneklemi katıldı. Çalışma öncesinde, Uşak Üniversitesi, Sağlık Bilimleri Bilimsel Araştırma ve Yayın Etik Kurulu'ndan 2017/1 numaral1, 08/02/2017 tarihli etik kurul onayı alındı ve sporcular çalışmaya katılmadan önce çalışmanın yararları ve riskleri hakkında bilgilendirilerek gönüllü onam formunu imzalatıldı. Çalışma Helsinki Deklarasyonu ilkeleri uyarınca gerçekleştirildi.

\section{Veri Toplama Aracı}

Katılımcılar daha önce herhangi bir foam roller uygulamasına katılmamış rekreasyonel olarak aktif olan futbolcular olarak belirlendi. Çapraz randomize olarak tasarlanan çalışmada, katılımcılar, 5 gün ara ile üç farklı egzersize katıldı ve her bir deneme günün aynı saatinde (16:0018:00) gerçekleştirildi. Tüm katılımcılar, ölçümlerden 48 saat öncesinde alkol ve kafein tüketmemeleri ve şiddetli egzersiz yapmamaları konusunda uyarıldı.

Çalışma aşağıdaki şekilde tasarlandı;

1. Gün, sporcuların antropometrik ölçümleri alındı ve Vyper Titreşimli Foam Roller alıştırma egzersizleri uyguland.

2. Gün, $5 \mathrm{dk}$ aerobik koşu ve dinamik gerdirme egzersizleri (AR+DG) uygulandı. 
3. Gün, $5 \mathrm{dk}$ aerobik koşu ve kendi kendine myofasial gevşetme (AR+KKMG) egzersizleri uyguland1.

Her iki ısınmanın ardından sporculara her test için submaksimal 2 deneme yapmalarına izin verildi ve $2 \mathrm{dk}$ pasif dinlenmenin ardından testler arasında 30 sn dinlenme araları ile esneklik ve sıçrama performansları değerlendirildi. Aynı testlerde ölçümler arasında 15 sn dinlenme arası verildi. Testlere başlamadan önce, sporculara testin amacı ve nasıl gerçekleştirileceği sözlü olarak anlatıldı ve uygulamalı olarak gösterildi.

Dinamik Germe Egzersizi: $5 \mathrm{dk}$ hafif koşu ve ardından yüksek diz çekmeler, Frankenstein ve sprintlerden oluşan dinamik gevşetme egzersizlerini içeren toplam $10 \mathrm{dk}$ 1sınma egzersizleri yaptırıldı (Avila, 2015).

Kendi Kendine Uygulanan Miyofasiyal Gevşetme Egzersizi: Foam Roller 1sınma protokolü, 5 dakikalık hafif koşuya ek olarak, vücudun her iki tarafına hamstring, quadriceps, gluteus ve gastrocnemius kaslarına 10 saniye pasif dinlenme araları ile 30 saniyelik kendine kendine miyofasiyal gevşetme (KKMG) egzersizleri olarak uygulandı. Uygulama hızı $38 \mathrm{HZ}$ olarak ayarlandı (Şekil 1 ve Şekil 2).

Sıçrama performansı, Aktif Siçrama (AS) ve Skuat Sıçrama (SS) olmak üzere iki farklı sıçrama testi şeklinde SmartJump (Jumpmetre) ile değerlendirildi. Sporcular, sıçrayış esnasında mümkün olduğunca mat üzerinde aynı yere düşmesi için sporcular karşılarında sabit bir noktaya bakmaları konusunda uyarıldı. AS ve SS testleri iki kez tekrarlandı ve en iyi değerler dikkate alındı (Lockie ve ark., 2017). Skuat sıçramada, sporculardan elleri belinde, çift ayakla matın üzerinde dizler $90^{\circ}$ skuatta olacak şekilde aşağıya doğru bir hareketi olmadan maksimal kuvvet uygulayarak yukarı doğru dik olarak sıçramaları istendi. Aktif sıçramada ise, alt ekstremiteyi izole etmek ve tekniğin katkısını ve kolların salınımını (Hara ve ark., 2008) ortadan kaldırmak için katılımcılardan tüm aktif sıçramalarda sporcular elleri belinde, dik duruş pozisyonundan aşağı doğru hızla çöküp yukarı doğru maksimal kuvvet ile sıçramaları istendi. Testler sonrasında, ölçülen sıçrama yükseklikleri cm cinsinden kaydedildi. Sporcular mümkün olduğu kadar yükseğe sıçrayabilmeleri için sözlü olarak cesaretlendirildi. Düşüş sonrasında, sporcuların her iki ayağı yere sabitlenmiş halde pozisyonda kalmaları istendi ve dengeyi kaybettiklerinde sıçramalar geçersiz sayıldı. Her test iki kez tekrar edilerek en yüksek olan değer cm cinsinden kaydedildi. 
Esneklik performansı, test, alt yüzünün uzunluğu $35 \mathrm{~cm}$ üst yüzeyinin uzunluğu $55 \mathrm{~cm}$ eni 45 ve boyu $32 \mathrm{~cm}$ ölçüsünde bir sehpa kullanılarak gerçekleştirildi. Katılımcı çıplak ayakla ayakları test kutusuna ve dizleri tamamen uzatılmış şekilde oturtuldu. Sırasılyla, test süresince dizlerin tam uzatılmasını sağlamak için, araştırmacı tarafından her iki diz elle aşağı itildi. Daha sonra, katılımcı bir elini diğerinin üzerine koyar ve parmaklarını ölçüm sehpası boyunca kaydırarak olabildiğince ilerletti. Bu şekilde en uzak noktada, öne ya da geriye esnemeden 1-2 saniye bekletildi. Test iki kez tekrar edilerek en yüksek olan değer $\mathrm{cm}$ cinsinden kaydedildi.

\section{Verilerin Analizi}

Çalışmadan elde edilen değerlerin istatistiksel analizi IBM SPSS (Ver. 23) analiz programı kullanılarak yapıldı. İlk olarak verilerin aritmetik ortalaması, standart sapma değerleri hesaplandı. Her bir değişkene ait \%95 güven aralığı hesaplandı. AR+DG ve AR+KKMG uygulamaları arasındaki farkın değerlendirilmesinde ise Wilcoxon Signed-Rank testi kullanıldı. Anlamlılık düzeyi $\mathrm{p}<0,05$ olarak yorumland.
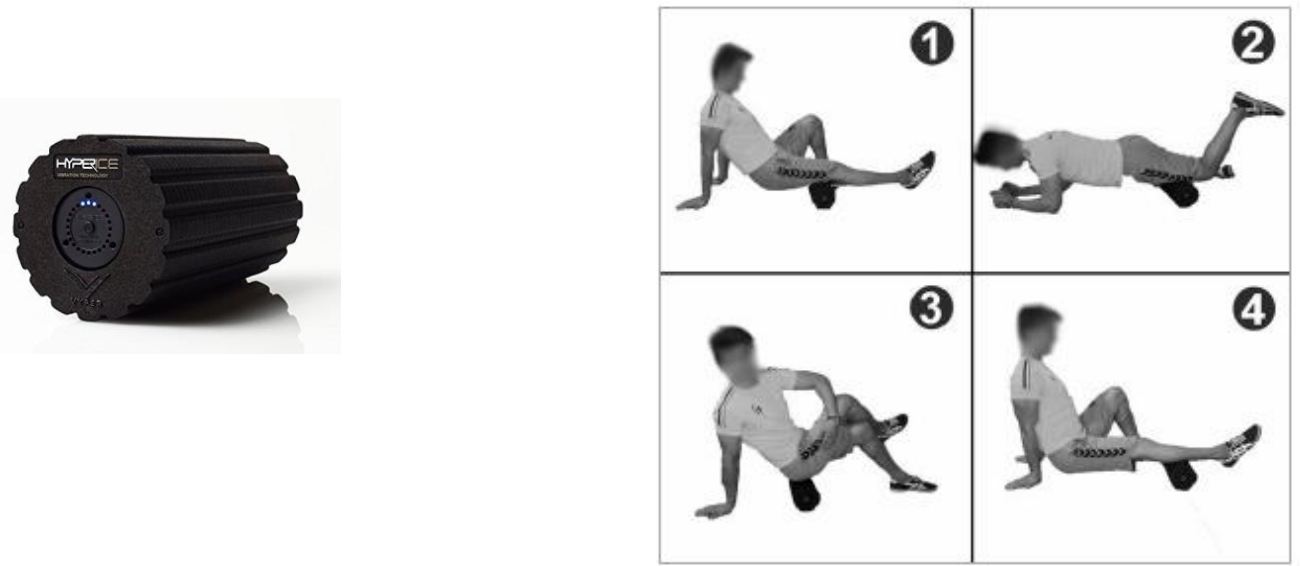

Şekil 1. Vyper Titreşimli Foam Roller Cihazı
Şekil 2. Vyper Titreşimli Foam Roller Uygulaması (Sağıroğlu, 2017). 


\section{BULGULAR}

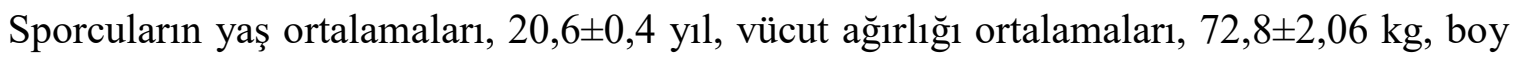
uzunluk ortalamaları, $175,4 \pm 1,42 \mathrm{~cm}$ ve BKİ ortalama değerleri $23,8 \pm 0,91 \mathrm{~kg} / \mathrm{m}^{2}$ olduğu tespit edildi (Tablo 1).

Tablo 1. KKMG katılımcılarının tanımlayıcı özelliklerinin ortalama \pm SS ve $95 \%$ güven aralığı değerleri $(n=12)$.

\section{Değişkenler}

Yaş (y1l)

Kilo (kg)

Boy $(\mathrm{cm})$

BKİ $\left(\mathrm{kg} / \mathrm{m}^{2}\right)$
Art. Ort. \pm Std. Sp.

$20.6 \pm 0.4$

$72.8 \pm 2.06$

$175.4 \pm 1.42$

$23.8 \pm 0.91$
95\% Güven Aralığı (CI)

Alt-Üst değer

$68.2-77.5$

$172.2-178.7$

$21.7-25.8$

Tablo 2. Katılımcılarının farklı ısınma protokolleri sonrasında esneklik ve sıçrama performans ortalamalarının karşılaştırılması $(\mathrm{n}=12)$.

(AR+DG)

Değişkenler

Esneklik (cm)

AS (cm)

$\mathrm{SS}(\mathrm{cm})$
Art. Ort. \pm Std. Sp.

$16.1 \pm 4.86$

$43.5 \pm 4.3 *$

$40.3 \pm 4.52$

\section{(AR+KKMG)}

Art. Ort. \pm Std. Sp.

\footnotetext{
$* \mathrm{p}<0,05$
}

$\mathrm{AR}+\mathrm{DG}$ ve $\mathrm{AR}+\mathrm{KKMG}$ isinma protokolleri arasinda sadece AS performansinda istatistiksel olarak anlamlı bir fark gözlemlendi $(\mathrm{z}=-2,67, \mathrm{p}<0,05)$. AS performansı, uygulanan AR+DG 1sınma protokolü sonrasında daha yüksek tespit edildi (Tablo 2).

\section{TARTIŞMA VE SONUÇ}

$\mathrm{Bu}$ çalışmada, genç erkek sporcularda KKMG egzersizlerinin ve DG egzersizlerinin esneklik ve iki farklı dikey sıçrama performansı üzerine akut etkisi incelendi. Elde edilen veriler sonucunda, AS yüksekliği DG egzersiz uygulamasından sonra anlamlı olarak daha yüksek 
bulundu. Diğer parametrelerde, esneklik ve SS değerlerinde, anlamlı bir sonuç elde edilemedi. Çalışmamızda elde edilen verilerin aksine, Peacock ve ark., 2014'te, 11 antrenmanlı erkek sporcuda yaptıkları çalışmada, tüm vücut dinamik ısınma ile tüm vücut foam roller uygulamalarının esneklik, güç, kuvvet, çeviklik ve hız performansı üzerine akut etkilerinin karşılaştırıldığı çalışmada, foam roller uygulaması sonrası güç, kuvvet, çeviklik ve hız performansının dinamik egzersizlere göre daha yüksek olduğu tespit edilmiştir. İki uygulama arasındaki esneklik performansında ise benzer sonuçlar elde edilmiştir. Yine, Sağıroğlu (2017) erkek futbolcularda yapmış olduğu çalışmada, alt ekstremiteye kendi kendine uygulanan titreşimli foam roller egzersizlerinin alt ekstremite patlayıcı kuvveti ve esneklik performansı üzerine etkisini incelemiştir. Sonuç olarak titreşimli foam roller egzersizlerinin hem dikey sıçrama hem de esneklik performansında istatistiksel olarak anlamlı bir fark göstermiştir.

Başka bir çalışma olan Jones ve ark., (2015)'de rekreasyonel olarak aktif 20 erkek katılımcı ile yapmış oldukları çalışmada, foam roller egzersizlerinin dikey sıçrama performansı üzerine akut etkisini incelemişlerdir. Dinamik ısınma ve dinamik ısınmaya ek olarak foam roller uygulaması sonucunda, dikey sıçrama performansında anlamlı bir farklılık tespit edilememiştir. Moran ve ark., (2018)'de atletlerde yaptıkları çalışmada masajın hızlanma ve sprint performansı üzerine etkisine bakmışlardır (60 m - 100 m ve 200 m). Çalışmaya dinamik ısınma, masaj, 1sınma kombinasyonu ve plasebo olmak üzere dört farklı ısınma protokolünü başarıyla tamamlayan 9 erkek, 8 kadın olmak üzere 17 atlet katılmıştır. Sonuç olarak ısınma grupları arasında anlamlı bir fark tespit edilememiştir. Okamoto ve ark., (2014), sağlıklı 7 erkek ve 3 kadınla yapmış oldukları çalışmada polistiren köpük roller kullanarak kendi kendine yapılan tüm vücut myofasial gevşetmenin arteryel sertlik ve vasküler endotelyal üzerine akut etkilerini incelemişlerdir. Kontrol ve çalışma grubunun her iki denemeden önce ve sonra arteryel foksiyonlardaki değişiklikler arasında anlamlı bir ilişki olduğunu tespit etmiş̧lerdir ( $\mathrm{p}=0.05)$. Yine, Su ve ark., (2017) yapmış oldukları çalışmada 15 erkek ve 15 kadın üniversite öğrencisinde, foam roller ile statik ve dinamik gerdirmelerin kas esnekliği ve kas gücü üzerine akut etkilerini incelemişlerdir. Sonuç olarak esneklik testi puanları, statik ve dinamik gerdirme ile karşılaştırıldığında foam roller uygulamasından sonra daha yüksek bulunmuştur. Kas kuvveti ile ilgili olarak, dinamik germe ve foam roller işleminden uygulamasından sonra, ancak statik gerilmeden sonra, sadece diz-gerginlik tepe torku (ön-karşımüdahale-sonrası) önemli ölçüde iyileştiğini tespit etmişlerdir. Sonuç olarak, foam roller, kas kuvvetini engellemeden quadriseps ve hamstringlerin akut olarak artan esnekliğindeki statik ve 
Yitik, R. ve Ateş, B. (2018). Foam roller kullanılarak gerçekleştirilen kendi kendine miyofasiyal gevşetme egzersizlerinin esneklik ve alt ekstremite gücü üzerine akut etkisi. CBÜ Beden Eğitimi ve Spor Bilimleri Dergisi, 13(2), 310-317.

dinamik gerilmeden daha etkili olduğunu ve sağlıklı genç yetişkinlerde isınmanın bir parçası olarak kullanabileceğini belirtmişlerdir.

Literatür incelendiğinde, uygulanan protokoller arasındaki metodolojik farklılıklar, bu alanda daha fazla araştırmanın gerekliliğini göstermektedir. Yapılan bu çalışma sonucunda, uygulanan KKMG egzersizlerinin ve DG egzersizlerinin esneklik ve siçrama performansları üzerine akut etkisi karşılaştırıldığında, AS yüksekliği DG egzersiz uygulamalarında anlamlı olarak daha yüksek olduğu, diğer parametrelerde ise, esneklik ve SS, anlamlı bir farklılık olmadığı belirlendi. Daha uzun yuvarlanma süreleri ve farklı performans parametrelerinin de test edilmesi önerilmektedir.

\section{KAYNAKLAR}

Barnes, M. F. (1997). The basic science of myofascial release: morphologic change in connective tissue. Journal of Bodywork and Movement Therapies, 1(4), 231-238.

Beardsley, C., \& Škarabot, J. (2015). Effects of self-myofascial release: a systematic review. Journal of Bodywork and Movement Therapies, 19(4), 747-758.

$\begin{array}{llllll}\text { Castiglione, } & \text { A. } & \text { (2010). } & \text { Self-myofascial therapy and }\end{array}$ http://www.180degrees.com.au/files/self_myofascial_release_therapy_and_athletes.pdf, Alıntılanma Tarihi: 10/02/2018

Depino, G.M., Webright, W.G., \& Arnold, B.L. (2000). Duration of maintained hamstring flexibility after cessation of an acute static stretching protocol. J Athl Train, 35(1),56-59.

Hara, M., Shibayama, A., Arakawa, H., \& Fukashiro, S. (2008). Effect of arm swing direction on forward and backward jump performance. Journal of Biomechanics, 41(13), 2806-2815.

Jones, A., Brown, L. E., Coburn, J. W., \& Noffal, G. J. (2015). Effects of foam rolling on vertical jump performance. International Journal of Kinesiology \& Sports Science, 3(3), 38.

Lockie, R.G., Moreno, M.R., Orjalo, A.J., Stage, A.A., Liu, T.M., Birmingham-Babauta, S.A., \& et al. (2017). Repeated-Sprint Ability in Division I Collegiate Male Soccer Players: Positional Differences and Relationships with Performance Tests. Journal of Strength and Conditioning Research. 1-27.

MacDonald, G.Z., Penney, M.D., Mullaley, M.E., Cuconato, A.L., Drake, C.D., Behm, D.G., et al. (2013). An acute bout of selfmyofascial release increases range of motion without a subsequent decrease in muscle activation or force. $J$ Strength Cond Res, 27(3), 812-21.

Manheim, C. J. (2008). The myofascial release manual (Fourth Edition). Slack Incorporated, USA.

Moran, R.N., Hauth, J.M., \& Rabena, R. (2018). The effect of massage on acceleration and sprint performance in track \& field athletes. Complementary Therapies in Clinical Practice, 30, 1-5.

Okamoto, T., Masuhara, M., \& Ikuta, K. (2014). Acute effects of self-myofascial release using a foam roller on arterial function. The Journal of Strength \& Conditioning Research, 28(1), 69-73.

Peacock C., \& Krein, T. (2014). An Acute Bout of Self-Myofascial Release in the Form of Foam Rolling Improves Performance Testing. Int. J. Exerc. Sci., 7(3), 202-211.

Power, K., Behm, D., Cahill, F., Carroll, M., \& Young, W. (2004). An acute bout of static stretching: effects on force and jumping performance. Med Sci Sports Exerc, 36: 1389-1396.

Renan-Ordine, R., Alburquerque-Sendín, F., Souza, D.P., Cleland, J.A., \& Fernández-de-Las-Peñas, C. (2011). Effectiveness of myofascial trigger point manual therapy combined with a self-stretching protocol for the management of plantar heel pain: a randomized controlled trial. J Orthop Sports Phys Ther, 41(2), 43-50.

Robertson, M. (2008). Self-myofascial release purpose, methods and techniques. Indianapolis: Indianapolis Fitness and Sports Training.

Sağiroğlu, İ. (2017). Acute effects of applıed local vıbratıon durıng foam roller exercıses on lower extremity explosıve strength and flexibility performance. European Journal of Physical Education and Sport Science, 3(11), 20-31.

Su, H., Chang, N.J., Wu, W.L., Guo, L.Y., \& Chu, I.H. (2017). Acute effects of foam rolling, static stretching, and dynamic stretching during warm-ups on muscular flexibility and strength in young adults. Journal of Sport Rehabilitation, 26(6), 469-477. 